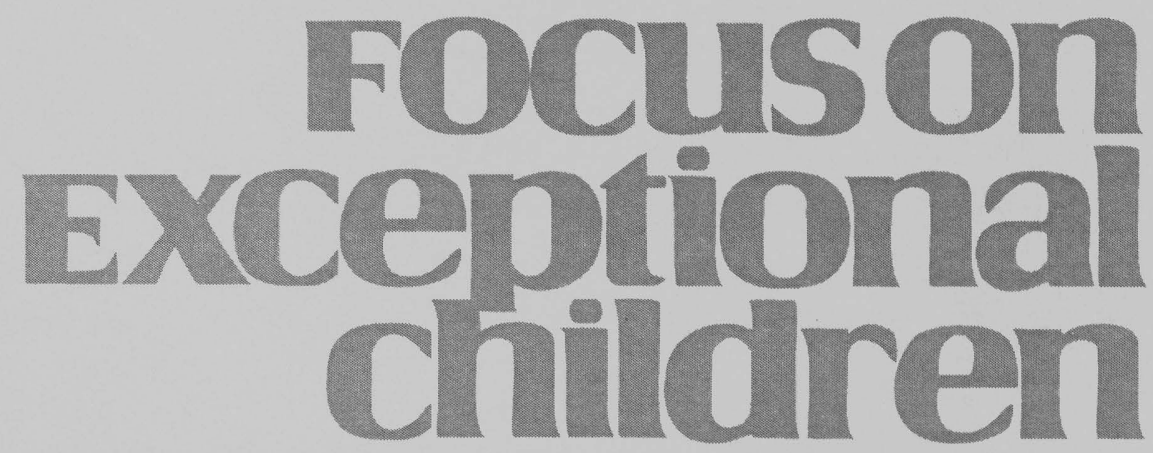

\title{
Creating Culturally Responsive Instruction: For Students' and Teachers' Sakes
}

\author{
Donna Y. Ford and Cathy D. Kea
}

The field of education faces a number of issues regarding how to improve the quality of school life and educational outcomes of culturally different ${ }^{1}$ students-namely African Americans, Hispanic Americans, and American Indians. All of the issues (high dropout rates, high suspension and expulsion rates, high rates of school failure, low test scores and grades, low academic engagement, poor student-teacher relationships, etc.) fall under the umbrella of three broad areas: the achievement gap, gifted education underrepresentation, and special education overrepresentation. Educators, administrators, and policy makers grapple daily with ways to resolve these issues and subissues but have yet to see much success on a large-scale and consistent basis.

Many studies and theories, along with personal speculation, have been advanced to explain the differential school performance of the aforementioned culturally different students. Likewise, a number of interventions, strategies, and recommendations have been put forth. A strongly advocated recommendation, especially by culturally different scholars, is that educators avoid colorblind/cultureblind approaches and philosophies and, instead, give more credence to creating culturally responsive classrooms (CRCs) for the culturally different students listed above.

The term culturally responsive can have numerous meanings and interpretations. At its core, it means responding proactively and empathetically to appeals, efforts, and influences. When we are responsive, we feel an obligation, a sense of urgency, to address a need so students will experience success. When teachers are culturally responsive, they are student centered; they break down barriers to learning and, hence, provide keys that open doors to students' success. Thus, to be culturally responsive means that teachers work proactively and assertively to understand, respect, and meet the needs of students from cultural backgrounds that are different from their own. Cultural responsiveness is the recognition that students are similar to, but also different from, each other.

\footnotetext{
' In this article we adopt the term culturally different rather than culturally diverse. Everyone has a culture; every group is culturally diverse. Instead, we propose that cultural differences are what contribute to misunderstandings, tensions, and frustrations.

Dr. Ford is a Professor in the Department of Special Education at Vanderbilt University. Dr. Kea is a Professor in the Department of Curriculum and Instruction at North Carolina Agricultural and Technical State University.
} 
One of the greatest challenges to being culturally responsive is the discomfort that often is experienced when the topic is "differences." It has been our collective experience that one of the most taboo topics in schools (and society at large) is that of "race" and associated terms - racism, discrimination, racial differences, and so forth. But, as Singleton and Linton (2005) assert, we must have courageous conversations about race in all of its manifestations. These democratic conversations (Fu \& Stremmel, 1999) are long overdue and, as with many (sensitive) issues, ignoring the topic will neither solve it nor make it go away.

Unfortunately, many people, professionals and laypersons alike, verbalize that they accept and/or appreciate that the world is diverse. They recognize that groups vary in language and other cultural aspects-values, beliefs, customs, and traditions-and that these differences contribute to miscommunication and misunderstanding. These feelings of difference - unfamiliarity, awkwardness, confusion, frustration, stress, and more-have been termed cultural shock (Oberg, 1954, 1960).

\section{Focuson
Exceptional children} lished monthly except June, July, and August as a service to teachers, special educators, curriculum specialists, administrators, and those concerned with the special education of exceptional children. This publication is annotated and indexed by the ERIC Clearinghouse on Handicapped and Gifted Children for publication in the monthly Current Index to Journals in Education (CIJE) and the quarterly index, Exceptional Children Education Resources (ECER). The full text of Focus on Exceptional Children is also available in the electronic versions of the Education Index. It is also available in microfilm from Serials Acquisitions, National Archive Publishing Company, P.O. Box 998, Ann Arbor, MI 48106-0998. Subscription rates: individual, \$48 per year; institutions, \$66 per year. Copyright (C) 2009, Love Publishing Company. All rights reserved. Reproduction in whole or part without written permission is prohibited. Printed in the United States of America. Periodical postage is paid at Denver, Colorado. POSTMASTER: Send address changes to:

Love Publishing Company

Executive and Editorial Office

P.O. Box 22353

Denver, Colorado 80222

Telephone (303) 221-7333

\section{EDITORIAL BOARD}

Steve Graham

Vanderbilt University

University of Nebraska-Lincoln

Eva Horn
University of Kansas
One need not travel outside of the United States to be shocked or to witness cultural differences. A foreign guest to one's home, for example, can be challenging and disconcerting (Ford, Harris, Tyson, \& Frazier Trotman, 2002; Ford $\&$ Whiting, 2008). How do we make these guests feel welcome, respected, appreciated, valued, understood? More to the point, what is a teacher to do when these foreigners, or guests, or culturally different individuals are their students? How might teachers make culturally different students (and families) feel comfortable, valued, and supported? How can teachers build effective relationships with these students? How can teachers communicate effectively with these students? What instructional strategies are effective and culturally compatible with their learning styles? What are some ways that teachers can make learning meaningful and relevant to these students?

The need to focus more assertively and proactively on students' cultures may be greater now than ever before in our nation's history. For generations, America has undergone major demographic changes, and our school demographics reflect these changes. Teachers and administrators cannot help but notice that the demographics of classrooms have changed in recent years. In 1972, students were predominantly White, representing some $78 \%$ of the public school student population, with the remaining $21 \%$ of students being culturally different-African American, Hispanic, Asian, and Native American (U.S. Department of Education, 2009). More recent data indicate that classrooms look very different now, not just in urban areas, but in suburban areas as well. That is, as of 2005 , approximately $42 \%$ of students were culturally different (U.S. Department of Education, 2007). How effective are traditional practices with this different or "nontraditional" student body? As professionals, we must ensure that all (not some, many, or most) students feel a goodness of fit in our classrooms.

In this discussion of change, we cannot ignore teacher demographics, which have remained relatively stable. The majority of teachers in $\mathrm{K}-12$ classrooms nationally are White $(83 \%)$ and female $(75 \%)$, according to the MiniDigest of Education Statistics (2006).

These changes in demography carry important implications for both teacher and student success. These changes raise questions about the usefulness of current practices and long-held traditions, and they raise questions for educators and decision makers about the continuation of traditional practices, practices that have privileged the status quo (i.e., White, middle-class students) and disadvantaged culturally different students (Blanchett, 2006; McIntosh, 1990). These student changes also raise questions about teachers' multicultural or cross-cultural efficacy in working with students from different backgrounds. Poor multicultural efficacy has been associated with teacher burnout and turnover in high-minority 
schools, as well as (over)referrals of culturally different students for special education evaluation, and over-representation of many of these groups in special education (Blanchett, 2006; Blanchett, Brantlinger, \& Shealey, 2005).

This article addresses the above issues and questions, with several goals. We seek to demonstrate the need for teachers to implement instruction that is culturally responsive, and we provide guidelines and strategies for developing culturally responsive instruction. To accomplish this, we (a) define and give a brief overview of culture, (b) describe the problems that students from different cultural backgrounds often have in academic environments, (c) examine some challenges in creating CRCs, (d) discuss fundamental characteristics of culturally responsive teachers, (e) present five key components of CRCs (The emphasis of this article, however, is on culturally responsive teaching, also referred to by others as "culturally relevant pedagogy," "culturally congruent instruction," or "culturally compatible instruction" for students with different culturally based learning styles and needs), and (f) share evidence-based instructional strategies effective with students from culturally different backgrounds, focusing on only one model because of space limitations. Toward the end of the article, we present the case of one student, James, to illustrate the information and recommendations provided herein.

\section{CULTURE: A DEFINITION AND BRIEF OVERVIEW}

If you don't manage diversity, it will manage you.

-L. R. Meriwether, (1993)

An underlying premise of this work is that miscommunication, cultural clashes, and disharmony stem largely from differences in culture. A second premise is that all students, not just culturally different students, should be exposed to a curriculum that is rich in diversity rather than ethnocentric or Eurocentric (Banks, 2006; Ford \& Harris, 1999).

We define culture as the beliefs, attitudes, values, habits, customs, and traditions shared by a group of people. We are not born with an innate culture; culture is learned or acquired. And culture has a significant influence on world views and behaviors (Hall, 1989; Hofstede, 2001). In this article we deliberately adopt a specific view of culture, focusing on culture relative to race rather than language, age, gender, socioeconomic status, region, or some other attribute (although each of these is important, too).

We recognize that cultural differences are not responsible for all clashes between people and groups; individual differences also contribute to misunderstanding and miscommunication. Figure 1 illustrates this point. The universal circle indicates that all humans have some commonalities: We are more alike than different. For instance, all humans eat, sleep, breathe, and bleed. All humans have a language or

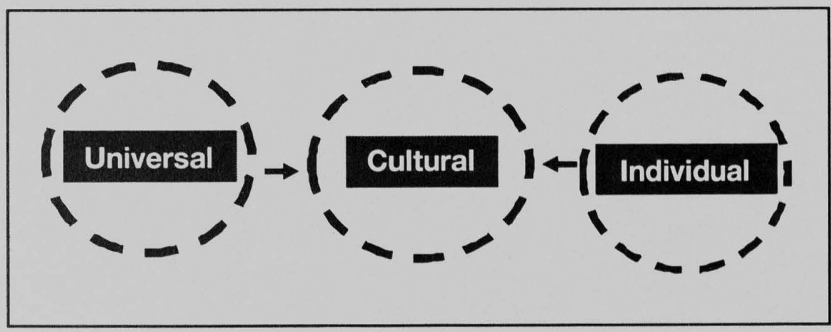

\section{FIGURE 1 \\ Relationships among Universal, Cultural, and Individual Aspects of Development}

method of communication, seek shelter, rear children, and have a need for safety.

When speaking of cultural practices, however, some of these universals must be qualified. This is where group differences come into play: What and how people eat, sleep, bring up children, communicate, and express emotions vary across cultures.

Finally, the individual circle reflects that no two people, even from the same culture (and family), will be identical, because of personality, interests, different experiences, and so on. Just as important, individual or personal influences can override the cultural influence. If all behaviors, values, and beliefs were placed along a continuum, those related to culture would fall in the middle, between universal and personal.

\section{CHANGING TRADITIONAL PRACTICES: SOME CHALLENGES}

Cultural clashes in classroom settings are inevitable. Yet, teachers can lessen cultural misunderstandings and miscommunication in classrooms by becoming more self-reflective, recognizing cultural differences between themselves and their students, striving to become more culturally competent, and creating classrooms that are culturally responsive rather than assaultive.

Some school districts and building-level administrators have acknowledged the importance, perhaps even urgency, of developing and hiring culturally competent teachers, while other schools and districts remain resistant or hesitant to even begin such discussions and training. Unconvinced of the academic and social merits of CRCs but simultaneously not wanting to appear "anti-diversity," some schools, at times with reservations, hold a workshop or two.

Mason (1993) placed cultural competence on levels, noting that individuals and organizations can range from being culturally destructive to competent (see Figure 2). Neither student nor teacher can benefit from an environment at the three lowest levels (destructiveness, incapacity, 


\section{COMPETENCE}

Acceptance and respect of cultural differences, continued self-assessment, attention to the dynamics of cultural differences, and adoption of culturally relevant service models.

\section{PRE-COMPETENCE}

Individuals and organizations move toward acknowledging cultural differences and making documented efforts to improve.

\section{BLINDNESS}

The system or organization provides services with the expressed intent of being unbiased.

They function as if culture makes no difference and all people are the same.

\section{INCAPACITY}

The system or agency does not intentionally seek to be culturally assaultive; lacks the skills/resources to work effectively/responsively with culturally different individuals/groups.

\section{CULTURAL DESTRUCTIVENESS}

Attitudes, policies and practices negatively affect diverse individuals and groups.

Source: adapted from Cultural Competence Self-Assessment Questionnaire, by J. Mason (Portland, OR: Portland State University, Multicultural Initiative Project, 1993).

\section{FIGURE 2 Levels of Cultural Competence}

and blindness). Undergirding the model is the recognition that overcoming resistance to change and letting go of the familiar is crucial to developing effective experiences that will increase teachers' multicultural competence and efficacy: It will provide teachers with the knowledge, dispositions, and skills to educate culturally different students effectively and equitably.

When teachers have the benefit of extensive and longterm multicultural professional development and multicultural teacher-education preparation, they are less likely to embrace cultural-deficit views (Ford \& Grantham, 2003; Irvine, 2003; Trent, Kea, \& Oh, 2008; Valencia \& Solórazano, 1997), are more confident, and believe they are effective in their instruction of culturally different learners
(Gay, 2002; Pang \& Sablan, 1998). They reach either levels of cultural precompetence or competence.

Despite increasing cultural differences in classrooms, educators continue to utilize pedagogy of the past-meaning strategies and techniques that were popularized when classrooms reflected less diversity relative to culture, economics, and language. Students need teachers who know whom they are teaching, what to teach, and methodologies to teach them (e.g., Ford \& Milner, 2006; Gay, 2002; Kea \& Utley, 1998; Ladson-Billings, 2009; Peske \& Haycock, 2006). Students need teachers who can use quality researchbased pedagogy that also is responsive to the learning, emotional, and social needs of culturally different students with and without exceptionalities.

Teachers must adapt instruction (their teaching styles and strategies) for students who are not benefiting from current instructional strategies and styles (Hale, 2001; LadsonBillings, 2009; Shade, Kelly, \& Oberg, 1997). In the field of medicine, when the intervention is ineffective (does not treat the problem, makes the problem worse, or shows no effect), the diagnosis, prescription, and treatment must be reevaluated, revised, and tailored to the patient. Likewise, in education, practices should be responsive to students-their values, interests, needs, and cultural norms. Thus, the ultimate challenge for teachers is to become reflective and proactive practitioners who can connect, commit, and practice an ethos of care with culturally different students (Kea, CampbellWhatley, \& Richards, 2004). This challenge is achievable.

\section{FUNDAMENTAL CHARACTERISTICS OF CULTURALLY RESPONSIVE TEACHERS}

CRCs cannot be discussed without paying attention to characteristics of a culturally competent teacher or educator, but painting such a portrait is no easy task. Nevertheless, some fundamental characteristics can be identified and then built upon. Kea et al. (2004) and Villegas and Lucas (2002) identified six salient characteristics.

1. Sociocultural consciousness: Teachers understand that one's way of thinking, behaving, and being are influenced by race, socioeconomic status, and language. Therefore, teachers must continuously engage in critical self-analysis and reflective thinking to examine their own sociocultural identity and the inequalities in schools.

2. An affirming attitude toward students from culturally different backgrounds: Teachers inspect and confront negative attitudes they might have toward culturally different students and groups.

3. Commitment and skills to act as agents of change: Teachers understand the change process and obstacles 
to change, and they have skills for collaboration and ways of dealing effectively with issues and problems with a basis in cultural differences.

4. Constructivist views of learning: Teachers believe that all students are capable of learning and provide scaffolds for what students already know through their experiences. Constructivist teaching promotes critical thinking, problem solving, collaboration, and the recognition of multiple perspectives.

5. Learning about students: Teachers take the time to learn about their students, their experiences, home, and community. They recognize that this rich information will help build relationships, and they use these experiences in the context of teaching, learning, and assessment.

6. Culturally responsive teaching strategies: Teachers support the constructivist view of knowledge, teaching, and learning. As teachers help students to construct knowledge, they build on students' personal and cultural strengths and create inclusive classroom environments where every student feels a sense of empowerment, value, and membership.

Figure 3 highlights more specific characteristics that fall into one or more of the above fundamental, yet broadly defined, characteristics.

\section{COMPONENTS OF CULTURALLY RESPONSIVE CLASSROOMS}

At their core, CRCs are student centered and, by design and default, culture centered. A student-centered classroom does not exist if culture is ignored or disregarded in any way. Stated differently, as with gender, language, and socioeconomic status (SES), race must not be ignored, minimized, trivialized, or disregarded. In every classroom, culture matters, race matters, gender matters, language matters, and SES matters.

CRCs are characterized by at least five components (see Figure 4): teachers' philosophy, learning environment, curriculum, instruction, and assessment (Banks, 2006; Ford \& Harris, 1999; Foster, 1995; Gay, 2000; Hale, 2001; LadsonBillings, 1994, 1995; Shade, 1989; Shade et al., 1997).

\section{Culturally Responsive Teaching Philosophy}

Teachers' beliefs and attitudes about teaching in general and teaching culturally different students in particular set the tone of the classroom (Kea, Trent, \& Davis, 2002). Teaching philosophies provide clues as to how teachers think learning occurs, how they think they can intervene in this process, what are their main goals for students, and what actions they take to implement their beliefs and intentions. To make culturally responsive classrooms a reality, teachers must incorporate a reverence for culture in their philosophy.

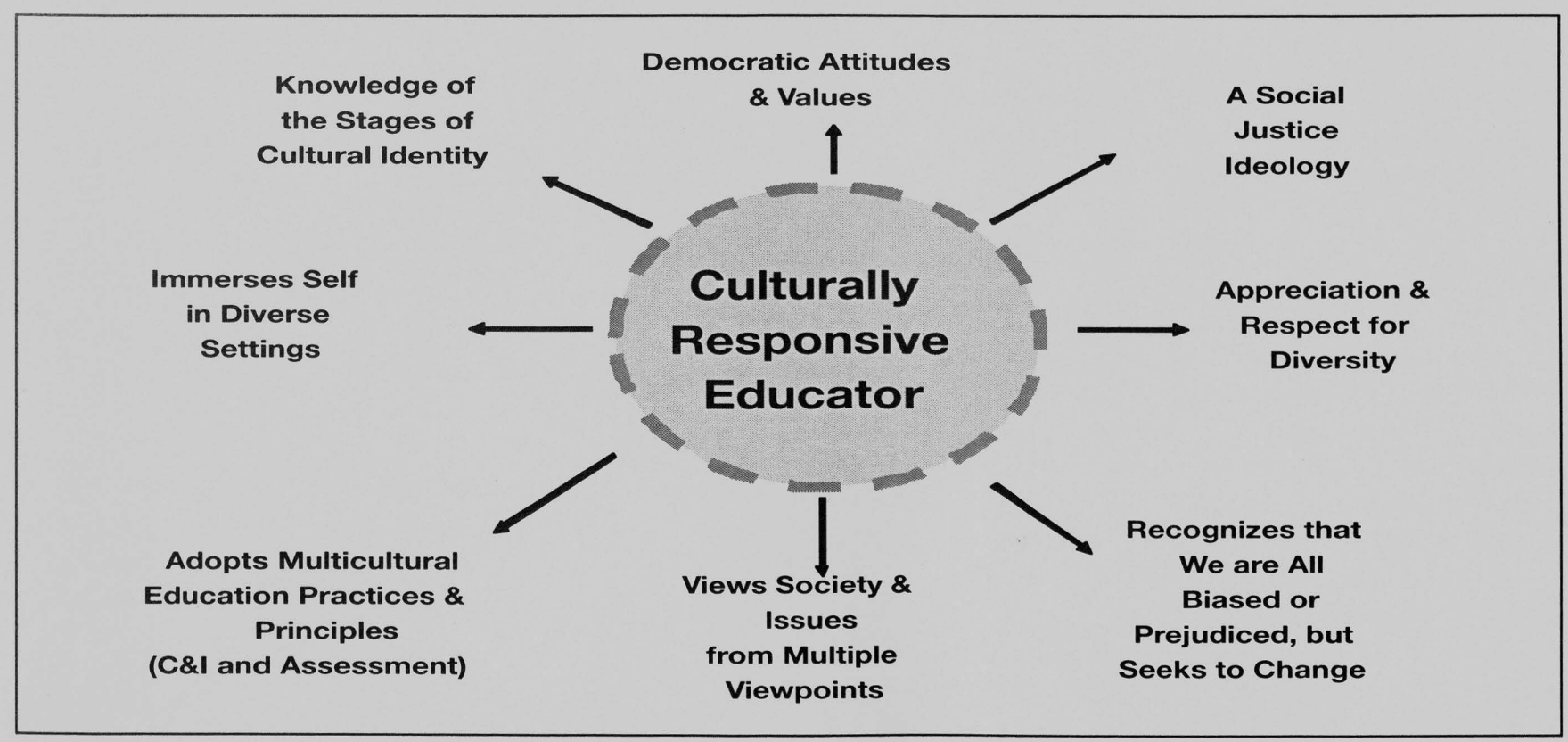

Source: Workshop handout, "Creating Culturally Responsive Classrooms,” by D. Y. Ford, 2007. 


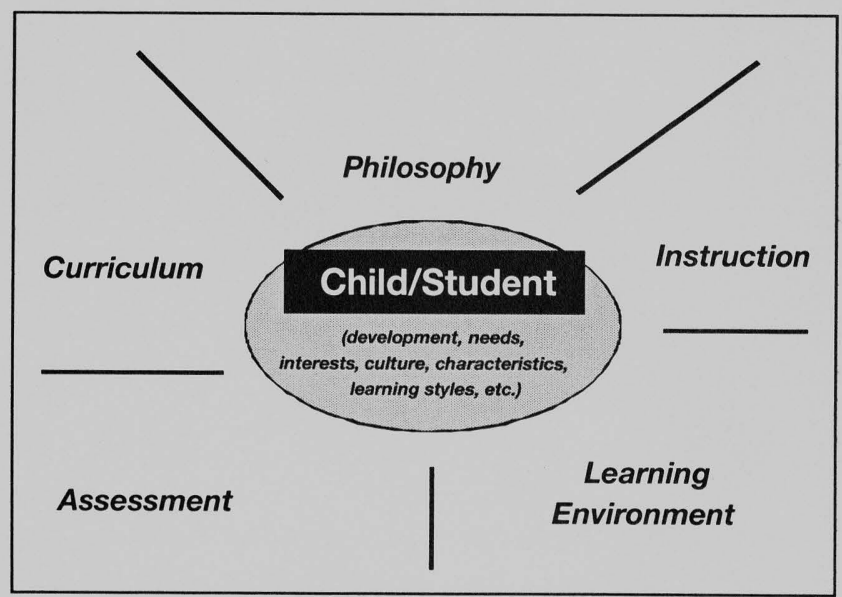

Source: Workshop Handout, "Creating Culturally Responsive Classrooms," by D. Y. Ford, 2007.

\section{FIGURE 4 \\ Components of Culturally Responsive Classrooms: Student Centered and Culture Centered}

The following questions can help teachers think about their culturally conscious teaching philosophy:

Do I have a colorblind philosophy?

Am I happy to work with students who are different from me culturally?

Do I care about all of my students?

Do I care if my students like, dislike, respect, or bond with me?

How do I make sure to hold high expectations for all students, regardless of their backgrounds and differences?

What do I need to change to be effective with my students?

\section{Culturally Responsive Learning Environment}

In a book aptly titled I Felt Like I Was From Another Planet, Dresser (1994) captures the essence of our notion of learning environment. Like teacher philosophy, the learning environment component of CRCs sets the context and climate for the classroom, which varies from one classroom to another. The learning environment is fundamentally about relationships, communication, and expectations-focusing specifically on students' sense of membership and belonging. It includes classroom management (e.g., RothsteinFisch \& Trumbull, 2008; Trumbull \& Rothstein-Fisch, 2008; Weiner, 2003; Weinstein, 2003; Weinstein, Curran, \& Tomlinson-Clarke, 2003), the aesthetic dimensions of the classrooms (e.g., photos, posters, other visuals), and materials (e.g., flesh-colored crayons, paints, drawing paper, and bandages).
Important questions for reflection and change are:

Are visual displays modern, nonstereotypical, and representative of all cultural groups in the classroom?

Are students and teachers respectful of each other?

Do all students feel a sense of belonging, appreciation, and support?

Are all students encouraged and expected to work collaboratively?

Are grouping arrangements for assignments and activities conducive to students from all backgrounds working together often?

Where are culturally diverse students seated in relation to the teacher and other students (those from same and different backgrounds)?

Do I discipline students equitably?

\section{Culturally Responsive Assessment}

In this era of high-stakes testing, we cannot ignore how we evaluate or assess all students and how we interpret their performance and scores. Given that too many culturally different students are not faring well when they are evaluated, teachers must create and use assessments that are culturally responsive (see Kea, Campbell-Whatley, \& Bratton, 2003; and Whiting \& Ford, 2006, for recommendations). Some central questions to consider include:

Are the measures valid and reliable for the specific culturally different group?

In what ways can teachers decrease bias in the measures (tests, checklists, forms, etc.) that they use or must adopt?

Have all students had opportunities to be evaluated in ways that are compatible with how they learn and communicate?

Thus, students are evaluated with tests but also have opportunities to show their learning via speeches, presentations, skits, research, and more. We recommend that teachers use dynamic assessments-a form of response to intervention (RTI) — as an option to assess student learning and guide instruction (see Green, McIntosh, Cook-Morales, \& Robinson-Zanarto, 2005). Dynamic assessment is proactive, optimistic, and responsive. The underlying assumption is that all students are capable of some degree of learning (i.e., change, modifiability). Dynamic assessment is not a single package or procedure but, rather, both a model and a philosophy for conducting assessments. One or more of the following dynamic assessment models is recommended:

1. An open-ended, clinical approach that follows the student, using generic problem solving tasks such as matrices. The approach to intervention focuses on 
principles and strategies for problem solving and promotes independent problem solving.

2. Generic, problem-solving tasks in which learners are offered a standardized intervention. All students are provided with the same intervention involving principles and strategies for problem solution. These approaches tend to emphasize classification of learners, attempting to reduce the negative results of cultural bias.

3. A graduated prompting procedure in which learners are offered increasingly more explicit hints in response to incorrect responses. All students progress through the same menu of prompts or hints, which vary with regard to the number of prompts required for task solution.

4. Curriculum-based approaches that use actual content from the student's educational program, with interventions based on best practices of teaching. These approaches can vary regarding degree of standardization of interventions, and they often emphasize IEP development for students with special needs.

\section{Culturally Responsive Curriculum}

The curriculum is the road map for what will be taught, when it will be taught, and the materials that will be used. When designing and using culturally responsive curriculum and materials or resources, rigor and relevance must be stressed (see Banks, 2008; Ford \& Harris, 1999). In a study of culturally different students who dropped out of school, the students ranked as the two primary factors (1) poor student-teacher relationships and (2) lack of relevance in the curriculum (Bridgeland et al., 2006). Worth noting is that more than $85 \%$ of these culturally different students had passing grades and could have graduated from high school if they had persisted.

Thus, when seeking to create curriculum that engages students and has meaning for them, the following questions, among others, should be considered (Banks, 2006; Ford \& Harris, 1999):

How have teachers tried to ensure that all students are interested, engaged, and motivated by what is taught?

In what ways can teachers make connections between what they must teach - the formal, written, mandated curriculum - and what students want to learn so it is relevant to students?

Have teachers presented a balanced, comprehensive, and multidimensional view of the topic, issue, and/or event?

Have multiple viewpoints been shared and discussed?

Have teachers addressed stereotypes, distortions, and omissions in the curriculum?
Is the curriculum rigorous? Does it challenge students and promote critical thinking and problem-solving skills?

Adapting the works of Banks (2006) and Schmitz (1999), we offer the following strategies for developing culturally responsive curriculum.

1. Define learning goals.

a. Determine what students in your field need to know; use deductive reasoning methods. Identify big ideas, generalizations, and theories that you want students to take away from the lesson.

b. Hold discussions and survey or interview students to learn about their interests and hobbies. Use this information to guide the lesson, readings, and related activities.

c. As you develop the lesson, choose activities, and select materials, think about what you want students to learn about themselves, their community, their classmates, and society.

2. Question traditional concepts and use transformational approaches.

a. Critique (when developmentally appropriate with students) how traditional curriculum has obscured, distorted, or excluded certain ideas, events, and/or groups.

b. Teach students how to be critical readers and consumers of information, using a transformational approach to curriculum. Include questions and materials that offer students more than one perspective of events, people, ideas, research, and so forth.

c. Incorporate new and contemporary research, theories, and models that address distortions, inconsistencies, discrepancies, and omissions.

3. Understand student diversity and differences, and adopt student-centered approaches.

a. Give thought to the kinds of diverse perspectives and experiences that students will bring to the learning situation (e.g., limited or extensive travel, international travel, community violence, family structure, socioeconomic status, literacyrich or poor home).

b. Assess students' prior knowledge and experiences through thoughtful discussions, surveys, and other information-collection methods.

c. Do not ask students to speak as representatives for "their" racial group.

d. Use constructive feedback to (re)teach to all students and build positive, mutually respectful relationships with them. 
4. Select materials and activities.

a. Go beyond the contributions approach (e.g., holidays, heroes, foods, fashion, and artifacts) to teach students about their culture and heritage and that of others.

b. Integrate new material so it is not simply an "addon." Infuse multicultural materials throughout all subject and content areas and lessons.

c. Consistently evaluate materials and resources for multicultural accuracy and authenticity. Highlight, discuss, and contradict stereotypes and all inaccuracies with students.

d. Make sure that visuals and resources are representative, including posters, photos, artwork, videos, books, music, crayons, paints, coloring/art paper, bandages, and the like.

e. Use a variety of teaching materials and activities to facilitate student engagement and learning (e.g., videos, guest speakers, books, poetry, mnemonic devices, songs, word walls, word games, simulations, stories).

\section{Evaluate effectiveness.}

a. Constantly critique the effectiveness of the lesson and materials. Make revisions that will facilitate student understanding, learning, and success.

b. Use mastery teaching strategies to assess student learning - pretest, teach, practice, test, revise lesson or activities, reteach.

c. Differentiate assessment using a variety of methods to gauge student learning and progress (e.g., presentation, discussion, verbal test).

\section{Culturally Responsive Instruction}

Whether one uses the term "teaching," "instruction," or "pedagogy," the central focus is on ensuring student learning and success. How compatible and responsive are teaching style(s) and learning styles? Which individual students or groups of students are not having school success when using traditional teaching styles and strategies? What changes can teachers make so that instruction is culturally responsive and compatible for all students?

Table 1 presents a comparison of traditional/colorblind teaching strategies and culturally responsive strategies. Culturally responsive teachers recognize and accept that cultural differences dictate modifications that are responsive to and address differences, as defined earlier. For instance, with culturally responsive instruction, teachers vary their teaching styles to accommodate and affirm learning styles, employ flexible grouping, collaborate more with students, and focus more on creating a climate that is cooperative and family-like.
According to Gay (2002), culturally responsive instruction (CRI) (or culturally relevant pedagogy or culturally congruent pedagogy) consists of using the cultural knowledge, prior experiences, and learning styles of culturally different students to make learning more appropriate and effective for them. She argues that CRI is validating to students, comprehensive and addressed in all subject areas, multidimensional with integration from various disciplines, empowering to students who learn to feel proud and efficacious, transformative in that it departs from traditional teaching when the latter is ineffective with students, and emancipatory in that students learn that there is no single version of truth. Thus, students have many opportunities to explore alternative, and even conflicting, perspectives, theories, paradigms, and research. More specifically, culturally responsive instruction respects students and honors their differences. It includes, but is not limited to, the following components or characteristics (Gay 2002):

\footnotetext{
1. CRI acknowledges the legitimacy of the cultural heritage(s) of culturally different groups, both as legacies that affect students' attitudes and approaches to learning, and as content worthy to be taught in the formal, mandated curriculum;

2. CRI builds or creates bridges of relevance between home, community, and school experiences;

3. CRI uses a range of instructional strategies that are connected to different learning styles, preferences, and needs;

4. CRI teaches students to know, respect, and appreciate their own cultural heritage, and the heritage(s) of others; and

5. CRI incorporates multicultural information, materials, and resources in all school subjects and activities. (p. 29)
}

We have selected one model and offer suggestions for creating instruction that is culturally responsive for African American students. Models for other groups are summarized in the work of Shade et al. (1997). Before presenting the model, two caveats are in order. First, the model is a guide, a framework focusing on modal characteristics that contains generalizations and evidenced-based findings designed to increase cultural understanding, appreciation, and respect, but not to promote stereotypes. As aptly stated by Shade et al. (1997):

\footnotetext{
When we speak of modal personality or style of a group, we are referring to traits that are most likely to be found in a sample of the population.... Designing a modal characteristic does not imply or assume that all or even most of the members of a particular culture share the same trait. Nor does this negate the idea that there are individual differences within the group. What we are describing are stylistic patterns that seem to be observed in large percentage of the population.... It provides educators a format for observation and for thinking about children from a different perspective. (p. 21)
}

Thus, it is vital to note that not all African Americans display all of these characteristics, some display a majority of these characteristics, and others display only a few. Like 


\section{TABLE 1}

\section{Traditional/Colorblind Teaching Strategies versus Culturally Responsive/Relevant Teaching Strategies.}

\section{Traditional/Colorblind Teaching Strategies \\ Culturally Responsive/ \\ Relevant Teaching Strategies}

Teaching style dominates; teacher-centered instruction

Teacher is the authority; teaching is primarily unidirectional-from teacher to students

\section{Lecture is the instructional norm}

Lecture is followed by testing (often paper and pencil tests)

Inflexible, homogeneous grouping prevails, based on students' skills and perceived ability

Independence and competition are valued and encouraged among students; individual work and autonomy are promoted

Abstract to concrete instructional style is the teaching process

Student success is the student's and/or caregiver's responsibility
Learning styles dominate; student-centered instruction

Teachers have expertise, but students can and do learn from each other; teaching is bi-directional-teachers can and must also learn from students; students also learn from each other

Lectures, debates, discussion, and other teaching methods are used to teach and reinforce learning

Lecture, discussion, activity, reinforcement, then testing/ assessment; several assessment options (mastery teaching)

Flexible grouping prevails based on students' skills and interests

Interdependence and cooperative learning are valued and encouraged among students; family-like atmosphere is promoted

The instructional style is concrete to abstract, with examples, stories, and visuals/graphic organizers, to make learning relevant

Student success is shared (e.g., teacher's responsibility, student's responsibility, and caregiver's responsibility). Collaboration is essential for students' success any model, this one offers a common framework from which to begin to better understand and work more effectively with African American students while remaining flexible in our thinking and never losing sight of individual differences. Just as important, we must acknowledge that individuals and groups from other cultural backgrounds can and do display one or more of the characteristics, but that these characteristics, to repeat, are often more evident in a student who is African American.

\section{Boykin's Afro-Central Model: One Framework for Culturally Responsive Teaching}

The culture of African Americans is an amalgamation of their African origins and the assimilation of various Anglo-European orientations to which they were exposed as involuntary immigrants (Ogbu, 1992). The bicultural patterns developed are those that help maintain their racial and cultural identity and help them to cope with living in a colorcoded society (Shade, Kelly, \& Oberg, 1997). These patterns have been studied extensively (e.g., Hale, 1982; Hollins, 1996; Irvine \& Armento, 2001; Ladson-Billings, 1994, 2009; Nobles, 1990). Boykin (1994; Boykin, Tyler, \& Miller, 2005; Tyler, Watkins-Lewis, \& Kizzie, 2006), however, clustered the modal characteristics into nine characteristics that provide concrete recommendations for creating culturally responsive teaching strategies and suggesting ways for teachers to modify their teaching styles.

Spirituality is common among African Americans and has been identified as playing a central role in their being resilient and coping with historical and contemporary 
oppression (e.g., slavery, prejudice, discrimination, poverty). This is a belief in a higher spiritual force or being who is ever-present in one's life and affairs. This belief represents, in some ways, an external locus of control in which faith plays a key role in explaining outcomes. A spiritually oriented culturally different student will attribute positive outcomes (e.g., good grade on an assignment, especially if the student felt unprepared) to being "blessed"; the student will be optimistic and resilient. Even though public schools may find themselves challenged at addressing spirituality because of the separation between church and state (and/or the non-religious focus in public schools), it behooves educators to be cognizant of this characteristic, even if they are not allowed legally to address it.

Harmony has at least two components. First, it relates to a desire and preference to be in sync with one's environment. It is a desire to "fit," to feel welcome, and to be a member of the community. In the classroom, harmony is evidenced by students' wanting to be appreciated and respected by teachers who value their presence and participation. Second, harmony relates to culturally different students having keen skills at reading the environment and nonverbal messages. In classrooms this can take the form of culturally different students' feeling that a teacher's words and actions are inconsistent or even contradictory. For example, a teacher who compliments these students without smiling or giving the student a pat on the back might be viewed as insincere.

Affect is characterized as an emotional orientation, often shown in the form of strong feelings. Affective-oriented culturally different students love strongly and hate strongly, for example. They are often sensitive, impulsive, and quick to express their feelings about classmates, teachers, and assignments. Teachers may view these culturally different students as immature and overly sensitive, as well as irrational.

Communalism is a family, social, external, and/or extraverted orientation. Students for whom this dimension is strong prefer to work interdependently, cooperatively, and in groups or with at least one other student. Communalism is indicative of a "we, us, our" philosophy in which one's primary reference group (family, friends, loved ones) is considered heavily in one's decisions. The individualistic, competitive orientation of many classrooms can be unmotivating or demotivating to these students, many of whom have been taught at home and in their community to take care of others, to give back. Teachers may view these culturally different students as overly social and lacking independence.

Movement represents a desire to be physically involved and active, or kinesthetically oriented. In the classroom setting, this can take the form of students' expressing a dislike for being sedentary and showing a preference and desire for active learning experiences (e.g., manipulatives, plays, skits, simulations, field trips). Teachers may misperceive culturally different students with this characteristic as "hyperactive" and lacking in self-control or self-discipline.

Verve is related closely to movement. The terms "energetic" and "lively" capture this dimension. In classrooms, vervistic students are often expressive, demonstrative, and easily excited or excitable. They like novelty and tend to get bored by a great deal of routine and predictability. As with movement, teachers may misperceive this characteristic as a lack of self-control.

Expressive individualism perhaps is best captured by the term "creative." Students with this characteristic are innovative, risk-taking, and spontaneous, and they enjoy being different or even dramatic. They often enjoy creative writing, acting, and opportunities to be risk takers and to be selfexpressive when completing tasks and assignments.

Oral tradition takes many forms, including a preference for oral modes of communication over other modes, as well as verbal virtuosity and bluntness or frankness. Students for whom this characteristic is strong tend to enjoy playing with words (e.g., jokes, puns, riddles, proverbs, poetry) and are solid orators and debaters. They are also likely to be frank and direct in expressing their ideas, likes, and dislikes. Teachers may view these culturally different students as talkative, lacking tact, or otherwise rude and disrespectful.

Social time orientation has been studied under the broader context of "polychronicity." For these students, time is not a commodity; instead, time is social. A focus on the present, the here and now, takes precedence over the future, which is not guaranteed. These students may be challenged or frustrated in completing assignments with required deadlines and within designated timeframes (e.g., 30 minutes). Teachers may perceive culturally different students as uncaring, disorganized, and ill prepared. Table 2 presents sample strategies based on the characteristics discussed above.

\section{PUTTING THIS WORK TO USE: JAMES' STORY}

In the following case, James is experiencing success with one teacher but not with others (Kea \& Trent, 2008). He shows interest and is well behaved in one class. What role do culture and/or personality play in these relationships, and his behaviors, interests, and achievement?

$$
* * *
$$

James, an eighth-grade student, was identified as having learning and behavioral challenges in the third grade. He currently lives with his grandmother because his mother is incarcerated and his father is unemployed and not able to take care of James financially. Although he is not living with his father, 
TABLE 2

Afro-Centric Teaching: Characteristics and Sample Strategies

\section{Characteristics}

- Movement

- Verve

- Harmony

\section{Sample Strategies}

- Encourage and build in opportunities for physical, tactile, and kinesthetic activities

- Creative movement, mime, dance, drama

- Role plays, simulations, tableau technique

Experiments

- Manipulatives

Field trips

- Lecture and teach using visuals (graphic organizers, black/white board, projector, PowerPoint, etc.)

- Incorporate poetry, creative writing, and journaling in lesson plans; use methods for teaching

- Incorporate music in the lesson plans

- Singing, humming, whistling, chanting

- Creating melodies, songs (all genres), etc.

- Playing instruments

- Music playing in background

- Teach through lectures

- Utilize seminars, discussions, and dialogues

- Give oral presentations and speeches

- Engage in debates

- Play word games (e.g., idioms, jokes, riddles, homonyms, anagrams)

- Introduce poetry

- Use storytelling and creative writing

- Involve the students in reading (choral, peer, individual)

- Incorporate journal writing

- Include social activities in lessons; use cooperative learning; use group work, projects, and assignments

- Provide opportunities for service and community involvement

- Offer opportunities for helping others (e.g., tutoring, mentoring)

- Provide deadlines with reminders; post deadlines

- Allow parts of assignment to be submitted at intervais

- Teach time management skills

- Use good organizational skills

- Connect lessons to students' interests, lives, background
James sees him at least once a week. Although James does have a positive, supportive family, his grandmother and father struggle to understand and help James academically and behaviorally. They encourage him to be assertive- to "speak his mind" by sharing his thoughts, opinions, likes and dislikes. Most of his teachers have found this forthrightness to be unsettling, disrespectful, and confrontational.
James received services in a self-contained BED class until the sixth grade. He now spends half of his day in general education classes and the other portion in the resource setting. His academic performance in reading and math are well below grade level, and his teachers report that he is often distracted, seldom focuses in class, has a difficult time following classroom rules, and rarely completes any 
assignments that are not of interest to him. Occasionally, James will respond in a "confrontational" manner to teacher directions or reprimands.

In contrast, the music teacher/band director describes James as cooperative, enthusiastic about music (playing the saxophone), and a central member of the marching band. The music teacher has never expressed concerns about James's behavior and academic engagement. In his class, James is allowed to voice his own views and is able to take constructive criticism and make appropriate changes to learning the assigned musical selections. Both James and the band director are avid sports fans who enjoy talking about the latest feats of their favorite teams.

\section{Suggestions for James' Teachers}

Teachers who are culturally competent recognize that behavior is socially constructed. Thus, when working with James, such teachers seek to understand the extent to which their interpretations of his behavior are subjective: Behavior means what we want it to mean; we assign meaning and value to behaviors. More poignantly, an emotional/ behavior disorder is whatever a culture's chosen authority figures designate as intolerable (Kauffman, 2005, p. 11).

Thus, one teacher may view James's open and direct expression of his opinion as appropriately assertive, proactive self-advocacy; and another teacher may view the same behaviors as aggressive, inappropriate, disrespectful, or confrontational. One teacher may appreciate that James wants teachers to get to know him (e.g., his interests, hobbies) and to build a trusting relationship with him; and another teacher may view such connections as irrelevant to the teaching-learning process.

The first step in the journey toward creating culturally responsive classrooms is for teachers to be self-reflective and to be honest regarding when they are effective and ineffective with a given student. This means paying considerable attention to their own responsiveness and effectiveness in meeting the needs of all students in their classrooms.

Applying the Boykin model to culturally responsive teaching, we recommend that James' teachers do the following (also see other suggestions for culturally responsive teaching in Crowe, 2009).

1. Reflect upon their views about culture and culturally different groups. Understand how culture operates in the classroom, affecting relationships, teaching, learning, and assessment. Examine their own biases and stereotypes about James and other culturally different individuals and groups and the source of these beliefs and attitudes.
2. Complete a teaching style inventory. Examine what seems to be effective and ineffective between their own style and how James learns. Consider and retain the strategies that facilitate and eliminate the strategies that hinder James' behavior and learning.

3. Get to know James better by calling and visiting his home and learning about his community. Attend community events.

4. Ask James about his interests and hobbies, and find ways to incorporate this information so learning can be meaningful and relevant to him (as his band teacher did).

5. Administer a learning-style inventory to James and other students. Compare the students' learning styles to teaching styles. Help James and his classmates learn ways to modify his learning style to different teaching styles.

6. Consider alternative ways to group and regroup James and classmates so learning will be more social and cooperative. Decrease individually oriented competition. Encourage students to be complimentary toward and supportive of each other. Encourage cooperation and collaboration.

7. Develop a sense of family or community with James and his classmates by working with them to develop a classroom name, logo, mascot, and motto. Use a collective voice often (e.g., we, us, our).

8. Communicate to James that you care about him personally and professionally. Use frequent praise and constructive feedback while being firm, consistent, and authoritative.

9. Allow James more opportunities to have choices in demonstrating his learning (e.g., test, project, speech, skit, poem, song). Support both verbal and nonverbal forms of expressing what has been learned (e.g., written test vs. oral test, presentation, debate).

10. Create activities and learning experiences that allow James to be an active, tactile, kinesthetic learner (e.g., manipulatives, plays, simulations, experiments, graphic organizers, field trips).

11. Connect lesson plans, activities, and discussions to James' interests, goals, aspirations, and personal life. Make learning meaningful, relevant, useful, insightful.

12. Give James opportunities to practice what he has learned, especially prior to assessing him.

13. Utilize films, videos, and speakers to reinforce what has been taught.

14. Use positive behavioral support strategies to proactively help James to develop more socially acceptable behaviors.

15. Hold problem-solving conferences with James. Establish rapport; talk about the problem; identify the 
problem and invite the student to solve it; explore possible causes; articulate a clear, specific goal; choose a solution.

\section{Connecting Culturally: James' Success}

Teachers can make a difference in the educational progress of culturally different learners by using culturally relevant instructional and behavioral interventions. In contrast, culturally irrelevant curricula may contribute to the misbehavior of these learners. The absence of culturally relevant instruction may actually be a primary factor associated with inappropriate student behavior (McKinney, Campbell-Whatley, \& Kea, 2005). James' success will depend largely on his teachers' ability to infuse culturally responsive activities throughout their lesson design and delivery. Teachers must

1. discover how student knowledge and daily lived community experiences relate to the curriculum content,

2. determine what aspect of the lesson matters to students, and

3. value the learners' knowledge and build on their strengths to improve instruction.

Information gathered from a brief interest inventory revealed James' interest in sports, music, and other entertainment venues involving popular personalities and stars. How might the teacher design culturally responsive reading and mathematical problems relating to these areas? "By providing meaningful reading materials encouraging honest debate, teachers can help African American adolescent males embrace the power of text" (Tatum, 2006, p. 41).

After reading Tatum's (2009) book, Reading for Their Life: (Re)Building the Textual Lineages of African American Adolescent Males, and utilizing the WestEd's Reading Apprenticeship framework, James' teacher selected four books by Caldecott Award-winning writer Walter Dean MyersBad Boy, Autobiography of My Dead Brother, Hoops, and Slam - to engage and provide instruction that would give shape and form to James' life. In addition, because James was playing the saxophone in the marching band, his music and classroom teacher worked collaboratively to expose James to the works of the Marsalis Brothers, Bela Fleck, and Kenny G., and required him to read their autobiographies, then select two of the musicians about whom to write a comparative analysis. This reinforced both his reading and writing skills.

The classroom teacher also selected various generational musical hits whose artists and genres were diverse. For example, the O'Jays, representing R\&B and Carrie Underwood, representing country music, were used to teach how to evaluate characterization through song. Likewise, James' ability to find solutions increased tremendously after combining the evidence-based metacognitive learning strategy FASTDRAW to teach word problems through NBA statistics, names of music and movie stars, and family and community lived experiences.

Further illustrating how to involve family members in the teaching and learning process and using community lived experiences, the teacher found that James and his grandmother were avid church-goers and the grandmother was in charge of budgeting and executing the weekly "Friday Fish Fry" at the church. The teacher wanted to link James's cultural background and rituals to the classroom content and devised this word problem scenario after collecting facts from his grandmother:

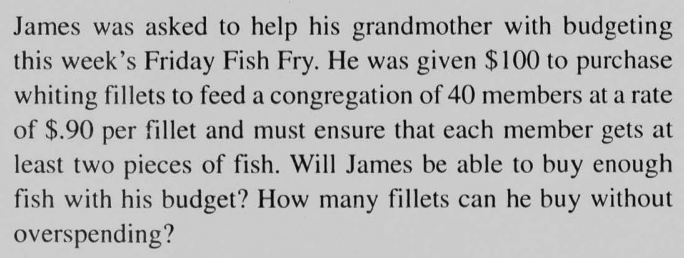
whiting fillets to feed a congregation of 40 members at a rate of $\$ .90$ per fillet and must ensure that each member gets at least two pieces of fish. Will James be able to buy enough fish with his budget? How many fillets can he buy without overspending?

Culturally relevant instruction sets the stage for learning in ways that facilitate cognitive engagement. Each day, teachers send verbal and nonverbal messages to students that underscore their capabilities for success. Teachers can make a tremendous difference if they concentrate on teaching the subject matter, use validated interventions and evidence-based best practices, and are able to link classroom content to students' lived and community experiences, demonstrating that culturally different students are learning. A culturally responsive learning community can be established if teachers build relationships with students and maintain a climate that is personally and physically inviting. It is essential that teachers reinforce academic development and accommodate and affirm cultural connections.

\section{SUMMARY AND CONCLUSION}

Many culturally different students are not experiencing school success, and too many find themselves in special education classrooms and settings. Teachers and administrators must consider how and the extent to which cultural differences-namely cultural clashes - contribute to these issues.

Teachers who wish to create the most effective and responsive classrooms for their students are guided by several principles. They (1) respect, honor, and validate individuals, groups, and their culture; (2) foster a collaborative learning and classroom environment in which relationships are valued and nurtured; (3) employ culturally responsive evaluations in which assessment is proactive and is used to guide instruction and promote student success and achievement; (4) adopt and use a multicultural curriculum that is 
rigorous and relevant; and (5) seek to ensure that teaching styles and instruction meet the learning styles and needs of students-no exceptions.

Designing culturally responsive activities for the classroom requires teachers to obtain information about the students' cultural background and their traditions and rituals, through formal and informal meetings with the student and family members. Teachers must encourage culturally different students to bring their community experiences into the classroom and link classroom content to these experiences. Teachers must display a caring attitude that reflects cultural awareness, to prevent misunderstandings that result in students' misbehavior and academic unresponsiveness, along with teacher frustration. The use of effective empirically validated instructional strategies will promote the acquisition, maintenance, and generalization of new skills and concepts (Kea \& Campbell-Whatley, 2005).

Culturally different learners will achieve both academically and socially if their teachers use a strengths-based approach and infuse cultural relevancy throughout the classroom. In sum, all teachers must be well grounded in a knowledge base of culturally different students and the diverse communities being served.

\section{REFERENCES}

Banks, J. A. (2006). Diversity in American education: Foundations, curriculum and teaching. Boston: Allyn \& Bacon.

Banks, J. A. (2008). Teaching strategies for ethnic studies. Boston: Allyn \& Bacon.

Blanchett, W. J. (2006). Disproportionate representation of African American students in special education: Acknowledging the role of White privilege and racism. Educational Researcher, 35(24), 24-28.

Blanchett, W. J., Brantlinger, E., \& Shealey, M. W. (2005). Brown 50 years later-Exclusion, segregation, and inclusion. Remedial and Special Education, 26(6), 66-69.

Boykin, A. W. (1994). Afrocultural expression and its implications for schooling. In E. R. Hollins, J. E. King, \& W. C. Hayman (Eds.), Teaching diverse populations: Formulating a knowledge base (pp. 243-256). Albany: State University of New York Press.

Boykin, A. W., Tyler, K. M., \& Miller, O. A. (2005). In search of cultural themes and their expressions in the dynamics of classroom life. Urban Education, 40, 521-549.

Boykin, A. W., Tyler, K. M., Watkins-Lewis, K. M., \& Kizzie, K. (2006). Culture in the sanctioned classroom practices of elementary school teachers serving low-income African American students. Journal of Education of Students Placed At-Risk, 11, 161-173.

Bridgeland, J. M., Dilulio Jr., J. J., \& Morison, B. (2006). The silent epidemic: Perspectives from high school dropouts. Washington, DC: Civic Enterprises.

Crowe, C. (2009). Solving thorny behavior problems: How teachers and students can work together. Portland, ME: Stenhouse.

Dresser, N. (1994). I felt like I was from another planet: Writings from personal experience. New York: Addison-Wesley.
Ford, D. Y., \& Grantham, T. C. (2003). Providing access for culturally diverse gifted students: From deficit to dynamic thinking. Theory Into Practice, 42, 217-225.

Ford, D. Y., \& Harris, J. J., III (1999). Multicultural gifted education. New York: Teachers College Press.

Ford, D. Y., Harris, J. J., III, Tyson, C. A., \& Frazier Trotman, M. (2002). Beyond deficit thinking: Providing access for gifted African American students. Roeper Review, 24(2) 52-58.

Ford, D. Y., \& Milner, H. R. (2006). Counseling high achieving African Americans. In C. C. Lee (Ed.), Multicultural issues in counseling: New approaches to diversity (pp. 63-78). Alexandria, VA: American Counseling Association.

Ford, D. Y., \& Whiting, G. W. (2008). Cultural competence: Preparing gifted students for a diverse society. Roeper Review, 30, 1-7.

Foster, M. (1995). African American teachers and culturally relevant pedagogy. In J. A. Banks \& C. A. M. Banks (Eds.), Handbook of research on multicultural education (pp. 570-581). New York: Macmillan.

Fu, V. R., \& Stremmel, A. J. (1999). Affirming diversity through democratic conversations. Columbus, $\mathrm{OH}$ : Merrill.

Gay, G. (2000). Culturally responsive teaching: Theory, research, \& practice. New York: Teachers College Press.

Gay, G. (2002). Preparing for culturally responsive teaching. Journal of Teacher Education, 53 (2), 106-116.

Green, T. D., McIntosh, A. S., Cook-Morales, V. J., \& RobinsonZanarto, C. (2005). From old school to tomorrow's schools: Psychoeducational assessment of African American students. Remedial and Special Education, 26(2), 82-92.

Hale, J. E. (1982). Black children: Their roots, culture, and learning styles. Provo, UT: Brigham Young University.

Hale, J. E. (2001). Learning while Black: Creating educational excellence for African American children. Baltimore: Johns Hopkins University Press.

Hall, E. T. (1989). Unstated features of the cultural context of learning. Educational Forum, 54, 21-34.

Hofstede, G. (2001). Culture's consequences: Comparing values, behaviors, institutions and organizations across cultures (2nd ed.). Thousand Oaks, CA: Sage.

Hollins, E. R. (1996). Culture in school learning: Revealing the deep meaning. Mahwah, NJ: Erlbaum.

Irvine, J. J. (2003). Educating teachers for a diverse society: Seeing with the cultural eye. New York: Teachers College Press.

Irvine, J. J., \& Armento, B. (Eds.). (2001). Culturally responsive teaching: Lesson planning for elementary and middle grades. Boston: McGraw-Hill.

Kaufman, J. (2005). Characteristics of emotional and behavioral disorders of children and youth (8th ed.). Columbus, OH: Merrill/ Prentice Hall.

Kea, C. D., \& Campbell-Whatley, G. D. (2005). Quality instruction as a means of preventing problems: Emerging best practices of classroom instruction. In L. M. Bullock \& R. A. Gable (Ed.), Effective disciplinary practices: Strategies for maintaining safe schools and positive learning environments for students with challenging behaviors (pp. 15-22). Reston, VA: Council for Exceptional Children.

Kea, C. D., Campbell-Whatley, G. D., \& Bratton, K. (2003). Culturally responsive assessment for African American students with learning and behavioral challenges. Assessment for Effective Intervention Journal, 29(1), 27-38.

Kea, C., Campbell-Whatley, G. D., \& Richards, H. V. (2004). Becoming culturally responsive educators: Rethinking teacher education 
pedagogy (Practitioner Brief Series). Tempe, AZ: National Center for Culturally Responsive Educational Systems.

Kea, C. D., Trent, S. C., \& Davis, C. P. (2002). African American student teachers' perceptions about preparedness to teach students from culturally and linguistically diverse backgrounds. Multiple Perspectives, 4 (1), 18-25.

Kea, C. D. \& Trent, S. C. (2008, April). Home on the range: Including families in differentiated instruction. Presentation at the meeting of the Council for Exceptional Children, Boston.

Kea, C. D., \& Utley, C. A. (1998). To teach me is to know me. Journal of Special Education, 32(1), 44-47.

Ladson-Billings, G. (1994). Dreamkeepers: Successful teachers for African-American children. San Francisco: Jossey Bass.

Ladson-Billings, G. (1995). But that's just good teaching! The case for culturally relevant pedagogy. Theory into Practice, 34(3), 159-165.

Ladson-Billings, G. (2009). Dreamkeepers: Successful teachers for African-American children. (2nd ed.). San Francisco: Jossey Bass.

Mason, J. (1993). Cultural competence self-assessment questionnaire. Portland, OR: Portland State University, Multicultural Initiative Project.

McKinney, S. E., Campbell-Whatley, G. D., \& Kea, C. D. (2005). Managing student behavior in urban classrooms: The role of teacher $\mathrm{ABC}$ assessments. Clearing House on Urban Education, 79(1), 16-20.

McIntosh, P. (1990, Winter). White privilege: Unpacking the invisible knapsack. Independent School, 49, 31-35.

Meriwether, L. R. (1993). Me and this thing called diversity: A personal plan. Colorado Springs, CO: Meriwether.

Mini-Digest of Educational Statistics 2006. (2006). Retrieved March 15, 2009, from http://nces.ed.gov/pubs2007/2007067.pdf

Nobles, W. W. (1990, January). Infusion of African and African American culture. Keynote address at annual conference, Academic and Cultural Excellence: An Investment in Our Future, Detroit Public Schools, Detroit, MI.

Oberg, K. (1954). Culture Shock. Report No. A-329. Indianapolis: Bobbs-Merrill Series in the Social Sciences.

Oberg, K. (1960). Adjustment to new cultural environments. Practical Anthropology, 7, 170-179.

Ogbu, J. U. (1992). Understanding cultural diversity and learning. Educational Researcher, 21, 5-13.

Pang, V. O., \& Sablan, V. A. (1998). Teacher efficacy: How do teachers feel about their abilities to teach African American students? In M. E. Dilworth (Ed.), Being responsive to cultural differenceshow teachers learn (pp. 39-58). Thousand Oaks, CA: Corwin Press.

Peske, H. G., \& Haycock, K. (2006). Teacher inequality. How poor and minority students are shortchanged on teacher quality. Washington, DC: Education Trust.
Rothstein-Fisch, C., \& Trumbull, E. (2008). Managing diverse classrooms: How to build on students' cultural strengths. Alexandria, VA: ASCD.

Schmitz, B. (1999). Transforming a course. CIDR Teaching and Learning Bulletin, 2(4), 1-2.

Shade, B. J. (Ed.). (1989). Culture, style, and the educative process. Springfield, IL: Charles C Thomas.

Shade, B. J., Kelly, C., \& Oberg, M. (1997). Creating culturally responsive classrooms. Washington, DC: American Psychological Association.

Singleton, G. E. \& Linton, C. (2005). Courageous conversations about race: A field guide for achieving equity in schools. New York: Corwin Press.

Tatum, A. W. (2006). Teaching reading to Black Adolescent males. Portland, ME: Stenhouse.

Tatum, A. W. (2009). Reading for the life: (Re)building the textual lineage of African American adolescent males. Portsmouth, NH: Heinemann.

Trent, S. C., Kea, C. D., \& Oh, K. (2008). Preparing preservice educators for cultural diversity: How far have we come? Exceptional Children, 74(3), 328-350.

Trumbull, E., \& Rothstein-Fisch, C. (2008). Cultures in harmony. Educational Leadership, 66(1), 63-66.

\section{STATEMENT OF OWNERSHIP, MANAGEMENT AND CIRCULATION}

Date of Filing: October 27, 2009

Title of Publication: Focus on Exceptional Children

Frequency of Issue: Monthly (except June, July \& August)

Location of Known Office of Publication: 9101 E. Kenyon Ave., Suite 2200, Denver, CO 80237

Location of Headquarters of Publisher: 9101 E. Kenyon Ave., Suite 2200, Denver, CO 80237

Name and Address of Publisher, Editor, and Managing Editor: Stanley F. Love, 9101 E. Kenyon Ave., Suite 2200, Denver, CO 80237

Owner: Love Publishing Company

Extent and Nature of Circulation: World Wide Academic

Total No. Copies Printed

Paid Circulation

Sales through Dealers, etc.

Mail Subscriptions

Other Classes Mailed Through USPS

Total Paid Circulation

Free Distribution Outside the Mail

Free Distribution

Total Distribution

Office Use and Left Over

Total

$\begin{array}{cc}\begin{array}{c}\text { Average No. Copies } \\ \text { Each Issue During } \\ \text { Preceding 12 Months }\end{array} & \begin{array}{c}\text { Single Issue } \\ \text { Nearest } \\ \text { Filing Date } \\ 1300\end{array} \\ 1300 \\ 38 & 38 \\ 1094 & 1094 \\ 15 & 15 \\ 1147 & 1147 \\ 38 & 32 \\ 95 & 71 \\ 1242 & 1218 \\ 58 & 82 \\ 1300 & 1300\end{array}$

I certify that the statements made by me above are correct and complete. 
U.S. Department of Education. (2007). Condition of education 2007. Washington, DC: Author.

U.S. Department of Education. (2009). Condition of education 2009. Washington, DC: Author.

Valencia, R., \& Solórzano, D. (1997). Contemporary deficit thinking. In R. Valencia (Ed.), The evolution of deficit thinking (pp. 160-210). London: Falmer.

Villegas, A. M., \& Lucas, T. (2002). Educating culturally responsive teachers: A coherent approach. Albany: State University of New York Press.

Weiner, L. (2003). Why is classroom management so vexing for urban teachers? Theory Into Practice, 42(4), 305-312.
Weinstein, C. S. (2003). Classroom management in a diverse society. Theory Into Practice, 42(4), 266-268.

Weinstein, C. S., Curran, M., \& Tomlinson-Clarke, S. (2003). Culturally responsive classroom management. Theory Into Practice, 42(4), 269-276.

Whiting, G. W., \& Ford, D. Y. (2006). Under-representation of diverse students in gifted education: Recommendations for nondiscriminatory assessment (Part 2). Gifted Education Press Quarterly, 20(3), 6-10. Retrieved March 9, 2009, from http://www.dynamic assessment.com/_wsn/page2.html

\section{PERMISSIONS AND COPYRIGHT}

All rights are reserved. No part of this publication may be reproduced, photocopied, faxed, stored in a retrieval system, or transmitted in any form or by any means, electronic, mechanical, recording or otherwise, without the prior written permission of the publisher.
Back issues are available for sale. Reproduction requires permission and payment of fees. It is illegal and a violation of federal copyright law to reproduce this publication without permission. Direct all inquiries to the permissions editor. 